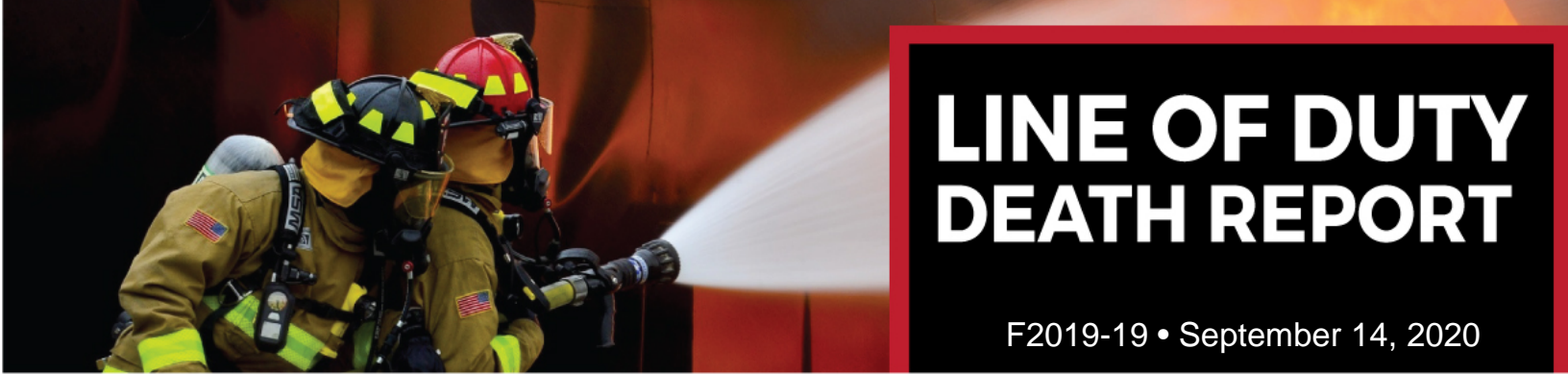

1000 FREDERICK LANE, MORGANTOWN, WV 26508 $\cdot 304.285 .5916$

\title{
While Maneuvering Outside His Apparatus, Firefighter Falls into Roadway and Is Struck and Killed by a Delivery Van - Texas
}

\section{Executive Summary}

On October 15, 2019, at approximately 0711 hours, a 49-year-old career male firefighter-paramedic was struck and killed by a delivery van. The firefighter's company, Aerial Platform 1, was dispatched at 0704 hours to assist Engine 1 with ventilation for light grey smoke and a burnt plastic odor in a hotel lobby. Aerial Platform 1 arrived on scene and parked in the southbound lane of a two-lane commercial street. All four crew members of Aerial Platform 1 gathered at the rear of the truck to unpack the electrical ventilation fans. None of them were wearing reflective vests over their station uniforms. As the crew of Aerial Platform 1 began to make their way toward the hotel, the captain asked the firefighter-paramedic to retrieve the thermal imaging camera (TIC) from the apparatus. At approximately 0711 hours, the firefighter-paramedic was near the

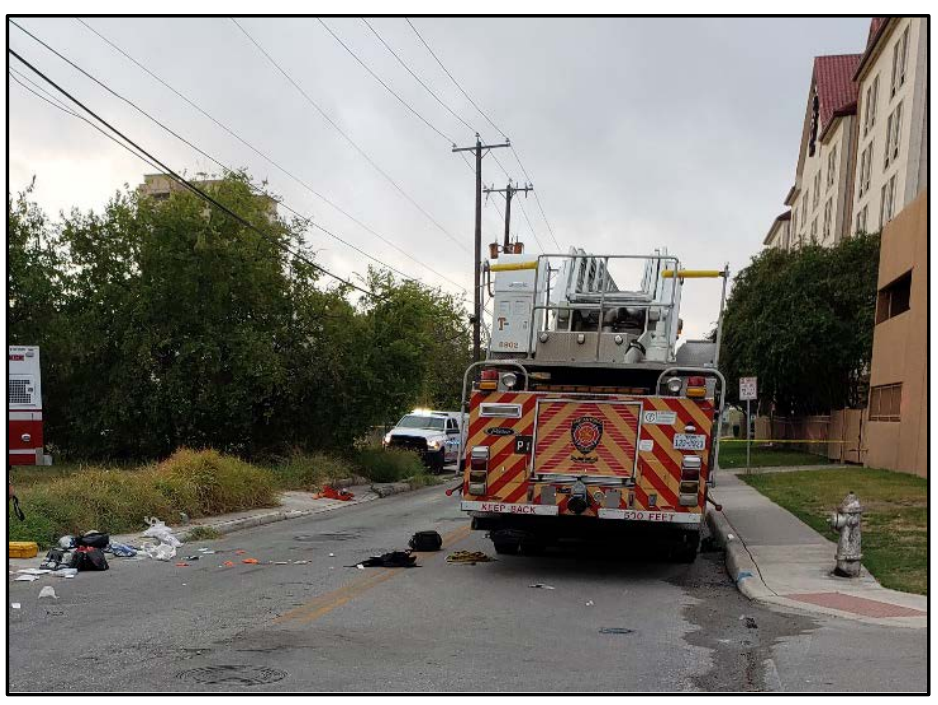

Aerial Platform 1 parked in the southbound lane of a two-way street. The firefighter-paramedic was struck in the northbound lane. (Photo courtesy of the Texas State Fire Marshal's Office.)

engineer's door of Aerial Platform 1, presumably to retrieve the TIC from its usual charging location on the console behind the engineer's seat. The delivery van was traveling northbound about 30 miles per hour (mph), the unposted speed limit. Visibility was poor due to the time of day (12 minutes before sunrise), dim and widely spaced streetlights, and Aerial Platform 1's emergency lights. As the van reached the front end of Aerial Platform 1, the firefighter-paramedic fell backwards into the northbound lane perpendicular to the engineer's door. It is unclear if he was about to enter the cab or had just exited the cab. The delivery van ran over the firefighter-paramedic, dragging him 26.5 feet before his body was released from the underside of the van. After slamming on the brakes and exiting the vehicle, the driver began screaming for help. Medics and firefighters from Engine 1 and Aerial Platform 1 found the firefighter-paramedic unconscious with severe trauma and began emergency 


\section{While Maneuvering Outside his Apparatus, Firefighter Falls into Roadway and Is Struck-by and Killed by a Delivery Van - Texas}

medical care. Despite immediate advanced life support administered on-scene, during transport, and in the local trauma center, the firefighter-paramedic succumbed to his injuries. The autopsy completed by the County Medical Examiner's office concluded the firefighter-paramedic "died as a result of blunt force injuries reportedly sustained as a pedestrian struck by a motor vehicle.”

\section{Contributing Factors}

- Lack of traffic incident management

- Lack of a reflective vest worn by firefighters over their station uniforms

- Lack of a temporary traffic control (TTC) plan

- Poor visibility

- The firefighter-paramedic's station boots may have been unzipped, presenting a slip/trip hazard

- The firefighter-paramedic may not have used three points of contact for access to/egress from the apparatus

- Use of a replacement apparatus, resulting in the firefighter-paramedic not being familiar with the TIC charging/storage location.

\section{Key Recommendations}

- Fire departments should train firefighters, especially firefighters in the jump seats, to exit and enter the apparatus from the side not facing oncoming or approaching traffic

- When not wearing turnout gear, fire departments should ensure firefighters wear reflective traffic safety vests whenever parking, working on, or crossing a roadway

- Fire departments should establish a TTC zone when apparatuses are parked or staged on twolane commercial or residential streets

- Once TTC measures are in place, fire departments should consider implementing procedures to turn off the apparatus headlights and reduce the flashing frequency of the emergency lights, particularly during the dark hours (dusk, night, dawn)

- Fire departments, along with their state and local partners, should consider a public education campaign on the state laws regarding speed limits around emergency operations, and the enforcement of those laws.

The National Institute for Occupational Safety and Health (NIOSH) initiated the Fire Fighter Fatality Investigation and Prevention Program to examine deaths of firefighters in the line of duty so that fire departments, firefighters, fire service organizations, safety experts and researchers could learn from these incidents. The primary goal of these investigations is for NIOSH to make recommendations to prevent similar occurrences. These NIOSH investigations are intended to reduce or prevent future firefighter deaths and are completely separate from the rulemaking, enforcement and inspection activities of any other federal or state agency. Under its program, NIOSH investigators interview persons with knowledge of the incident and review available records to develop a description of the conditions and circumstances leading to the deaths in order to provide a context for the agency's recommendations. The NIOSH summary of these conditions and circumstances in its reports is not intended as a legal statement of facts. This summary, as well as the conclusions and recommendations made by NIOSH, should not be used for the purpose of litigation or the adjudication of any claim.

For further information, visit the program website at www.cdc.gov/niosh/fire or call toll free 1-800-CDC-INFO (1-800-232-4636). 
NIOSH FIRE FIGHTER FATALITY INVESTIGATION AND PREVENUION PROGRAM

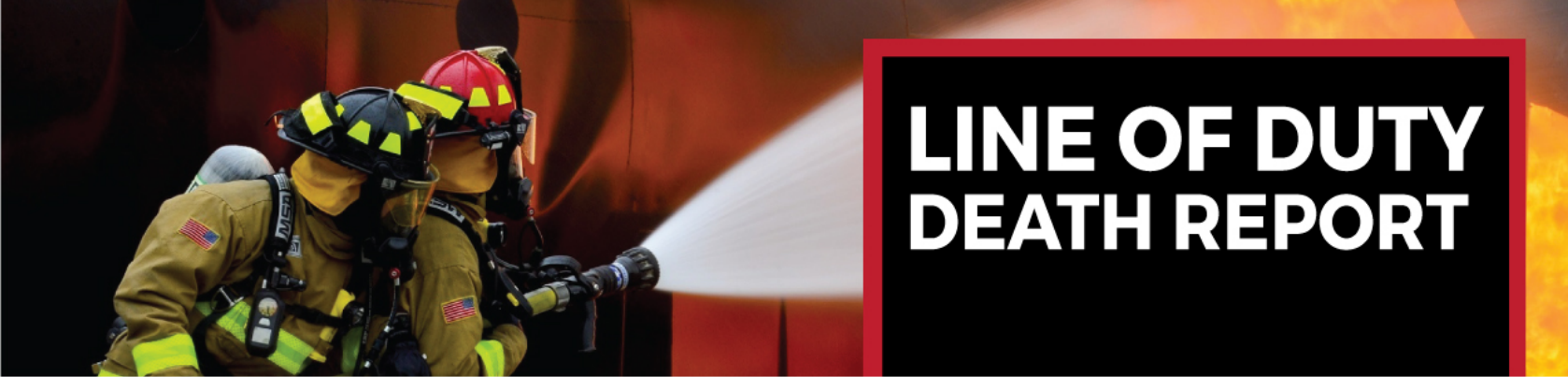

1000 FREDERICK LANE, MORGANTOWN, WV 26508 $\cdot 304.285 .5916$

\section{While Maneuvering Outside His Apparatus, Firefighter Falls into Roadway and Is Struck and Killed by a Delivery Van - Texas}

\section{Introduction}

On October 15, 2019, a 49-year-old male career firefighter-paramedic fell into the path of a motorist traveling the opposite direction on a two-lane roadway and was struck by the vehicle. On October 16, 2019, the U.S. Fire Administration notified the National Institute for Occupational Safety and Health (NIOSH) of this incident. NIOSH was also notified directly by the affected fire department on October 16, 2019. On December 9, 2019, a medical officer from the NIOSH Fire Fighter Fatality Investigation and Prevention Program traveled to Texas to investigate this incident. The NIOSH investigator met with the fire chief and other officers in the fire department, a representative from the State Fire Marshal's Office, a representative from the International Association of Fire Fighters local union, and the detective for the investigating police department. The NIOSH investigator inspected the incident site and took photographs. The NIOSH investigator interviewed members of the fire department involved in the incident, including the emergency medical services (EMS) personnel who treated the injured firefighter-paramedic on scene and transported the victim to the hospital. The NIOSH investigator also obtained copies of the firefighter-paramedic's training records, fire department standard operating procedures, dispatch audio records, apparatus maintenance records, and photographs and diagrams from the police investigation.

\section{Fire Department}

This career fire department employs 1,762 uniformed firefighters working out of 54 fire stations that serve a population of approximately 2.5 million residents in a geographical area of 461 square miles. The department is managed by three deputy chiefs who report directly to the fire chief.

Administratively, the fire department is organized into three major divisions: administrative services, support services, and emergency services. Each division is supervised by a deputy fire chief. Within the emergency services division, the fire department operates three fire suppression shifts that work 24 hours on and 48 hours off with a work schedule of 56 hours per week. Each shift is supervised by a fire shift commander. EMS personnel work 24 hours on, and 72 hours off. Fire suppression staff are organized into eight battalions.

Each shift has a captain assigned as the shift safety officer. The fire department maintains a pool of lieutenants who have been trained to fulfill the duties of the shift safety officer to ensure this position is always staffed. The battalion chief positions are field operations (fire suppression) positions. Every battalion chief is assigned an incident command technician. The shift commander is also assigned an incident command technician. If a battalion chief moves to an administrative position, their rank is changed to division chief. 


\section{While Maneuvering Outside His Apparatus, Firefighter Falls into Roadway and Is Struck and Killed by a Delivery Van - Texas}

The fire department has a passport system for personnel accountability tracking. In 2019, the fire department was accredited by the Commission on Fire Accreditation International and rated a Class 1 department by the Insurance Services Office (ISO). In the ISO rating system, Class 1 represents exemplary fire protection, while Class 10 indicates that the area's fire-suppression program does not meet ISO's minimum criteria.

All fire department emergency and non-emergency dispatches originate from the city's joint Fire and Police Emergency Dispatch Center. The Fire Dispatch Center processes approximately 560 calls per shift. Fireground audio is recorded.

\section{Training and Experience}

The state of Texas requires individuals seeking to become a firefighter to complete a commissionapproved basic structure fire suppression training program. This program consists of 468 hours of basic fire protection training, meeting the requirements of the Texas Commission on Fire Protection Basic Fire Suppression Curriculum. Each fire department and jurisdiction can require additional training.

This career fire department has established training requirements and operates its own training academy. The recruit training requirements meet or exceed the requirements of National Fire Protection Association (NFPA) 1001, Standard on Fire Fighter Professional Qualifications, Fire Fighter I and Fire Fighter II [NFPA 2019a] and the Texas Commission on Fire Protection Basic Fire Suppression Curriculum.

The fire department requires the following actions for an individual to become a firefighter:

- Step One - Application process: Applicants must be at least 19 years old but not have reached 34 years of age by the date of their entrance examination. Other application requirements include: applicants cannot have any felony convictions or convictions of other crimes involving moral turpitude, cannot have any discharge from the Armed Services other than honorable, must be a high school graduate or equivalent (GED), and must be able to read, write and speak the English language.

- Step Two - Candidate: Selected applicants must pass the department's candidate physical ability test (CPAT), clear a background investigation, pass a behavioral personal assessment examination, pass a polygraph examination, clear a psychological evaluation, and clear a medical physical examination.

- Step Three - Cadet: Successful candidates are in the fire department's cadet training program. To advance, cadets must: complete the 28-week fire department cadet training program (fire academy), earn Texas basic structural firefighter certification, and earn a National Registry EMT-B (Emergency Medical Technician Basic) certification.

- Step Four - Probationary Firefighter: The probationary period begins with entry into the fire academy and ends one year later. After meeting requirements listed in Step Three, 


\section{While Maneuvering Outside His Apparatus, Firefighter Falls into Roadway and Is Struck and Killed by a Delivery Van - Texas}

probationary firefighters are assigned to a battalion chief for most of their probationary period after graduation from the fire academy. Probationary firefighters are assigned to a specific station and company for their first ten shifts. After ten shifts at their initial assignment, probationary firefighters are rotated around at various stations and companies within their battalion. Probationary firefighters are periodically detailed to the fire academy for skills training and reinforcement drills. Probationary firefighters have a task book with checklists to be completed during their probationary period which include:

o Engine company checklist

o Ladder company checklist

o Standard operating procedures (SOP) familiarization checklist.

The training academy is staffed by 15 employees (13 firefighters and two civilians). An additional four firefighters are detailed to the academy as training officers on one-year training details.

After one year from the date of hire (start of fire academy class), the probationary firefighter is promoted to the rank of firefighter. All firefighters must complete Incident Command System (ICS) 100, ICS 200, ICS 700, and ICS 800. After three years from their date of hire, a firefighter is eligible to take an examination for promotion to the rank of engineer. After promotion to the rank of engineer, eligibility for promotion to each successive rank requires two years in rank:

- Firefighter

- Engineer

- Lieutenant

- Captain

- Battalion chief.

Assignments to the rank of assistant chief and deputy chief are appointed by the fire chief.

The fire department maintains a structured officer development program. Lieutenants and above are required to earn a Fire Officer I and Fire Instructor I certification. Captains and above are required to earn Fire Officer II certification. Battalion chiefs and above are required to earn a Fire Instructor II certification. The officer development process involves a mixture of online training modules plus three days of skillset training at the fire academy. Promotion of the firefighter to captain rank involves passing a written test of 100 questions. Promotion to the battalion chief rank involves a test that is $50 \%$ written and 50\% verbal assessment.

All firefighters are required to complete 20 hours of continuing education courses annually. This continuing education course content is accessed through an online learning management system. The fire department is training all officers to be Blue Card $\subset$ certified.

The firefighter-paramedic who died in this incident joined the department in February 2003. Over his 16-year career, he had completed the following trainings and certifications: Fire Fighter I, Paramedic, Hazardous Material Awareness and Operations, National Incident Management System (NIMS), 


\section{While Maneuvering Outside His Apparatus, Firefighter Falls into Roadway and Is Struck and Killed by a Delivery Van - Texas}

Incident Command System (ICS) series, Weapons of Mass Destruction series, Terrorism Awareness for First Responders, Incident Response to Terrorist Bombings, Structural Collapse Technician I, Pipeline Emergency Response, Flood and Swiftwater Rescue Technician I and II, Basic Rope Rescue Technician, Confined Space Rescue, Accident Scene Safety and Hands-on Extrication Training, Driving Safety, Workplace Diversity, Ethics, Sexual Harassment in the Workplace; HIPAA Security, Fire Fighter Safety - Injuries and Fatalities, Bloodborne Pathogens, Mass Decontamination, Reconnaissance, Respiratory Protection, Response to Illicit Drug Labs, Slips/Trips/Fall Prevention, Wildland-Urban-Interface Structure Defense, Hazard Communication Standard, Understanding Sexual Assault and Responding with Care, Suicide Bomber, Autism Awareness, Functional Approach to Physical Fitness for Emergency Responders, Building Construction, Chemical Protective Clothing, Company Officer Legal Responsibilities and Liabilities, Lifting and Back Safety for EMS Providers, Stress Management, Forecasting Events, Rethink Your Drink, Team Building, Terminating the Incident, Mayday Drills, Low Angle Rescue, Workers Compensation, Fire Hose, Drug Free Workplace, Driver Safety, Driver Distraction, Vehicle Characteristics, Forcible Entry, Protection of Evidence of Fire Origin and Cause, Water Supply, Pre-incident Planning, Narcotic Overdose for the EMT, Heat Illness and Emergencies, Wildland Fire Behavior, Firefighter Survival, Post-Incident Analysis, Equal Employment Anti-Harassment Course, Firefighting Hood Doffing Procedures, Elevator Operations, and Chemical Protective Clothing.

\section{Apparatus, Equipment, and Personnel}

On October 13, 2019, two days before their shift, Station 1's Aerial Platform (2013 Pierce Quantum Aerial Platform) was recalled for maintenance. The replacement apparatus (see Photo 1) was a 2005 Pierce Quantum Aerial Platform built to conform to the requirements of the 2003 edition of NPFA 1901, Standard on Automotive Fire Apparatus [NFPA 2003].

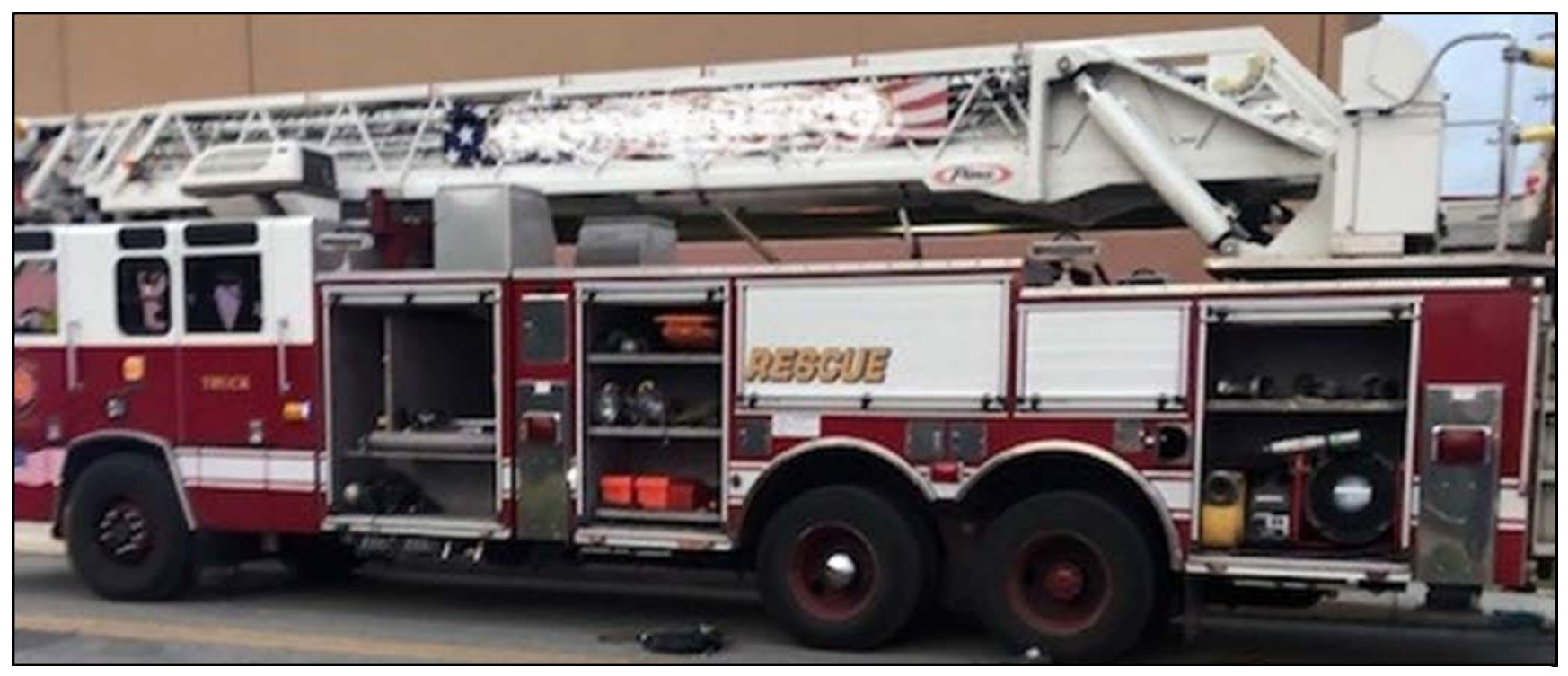

Photo 1. Replacement aerial platform. (Photo courtesy of the fire department.) 


\section{While Maneuvering Outside His Apparatus, Firefighter Falls into Roadway and Is Struck and Killed by a Delivery Van - Texas}

Relevant to this investigation, the replacement apparatus was compliant with:

- Section 15.7 (Stepping, Standing, and Walking Surfaces) addressing the: a) height and width of the cab steps, b) surface slip resistance of the steps, and c) testing methods to assess the slip resistance

- $\quad$ Section 15.8 (Access Handrails)

- Section 15.9.3 (Retroreflective Striping) [NFPA 2003].

The replacement apparatus was not in compliance with section 14.1.6 which states: "all driving and crew compartment doors shall have at least $96 \mathrm{in}^{2}\left(62,000 \mathrm{~mm}^{2}\right)$ of retroreflective material affixed to the inside of each door" [NFPA 2003], or the most recent 2016 edition which states in section 14.1.5: "Any door of the apparatus designed to allow persons to enter or exit the apparatus shall have at least $96 \mathrm{in}^{2}\left(62,000 \mathrm{~mm}^{2}\right)$ of retroreflective material affixed to the inside of the door” [NFPA 2016].

Although the replacement unit was the same make and model, it had some differences. The most important relevant to this incident was a different location for the TIC's charging station. The Aerial Platform normally assigned to Station 1 (the one they had been using for the past several months) had the TIC's charging station mounted on the console behind the engineer's seat (see Photo 2). The replacement Aerial Platform had the TIC's charging station bolted onto the floor behind the officer's seat (see Photo 3).

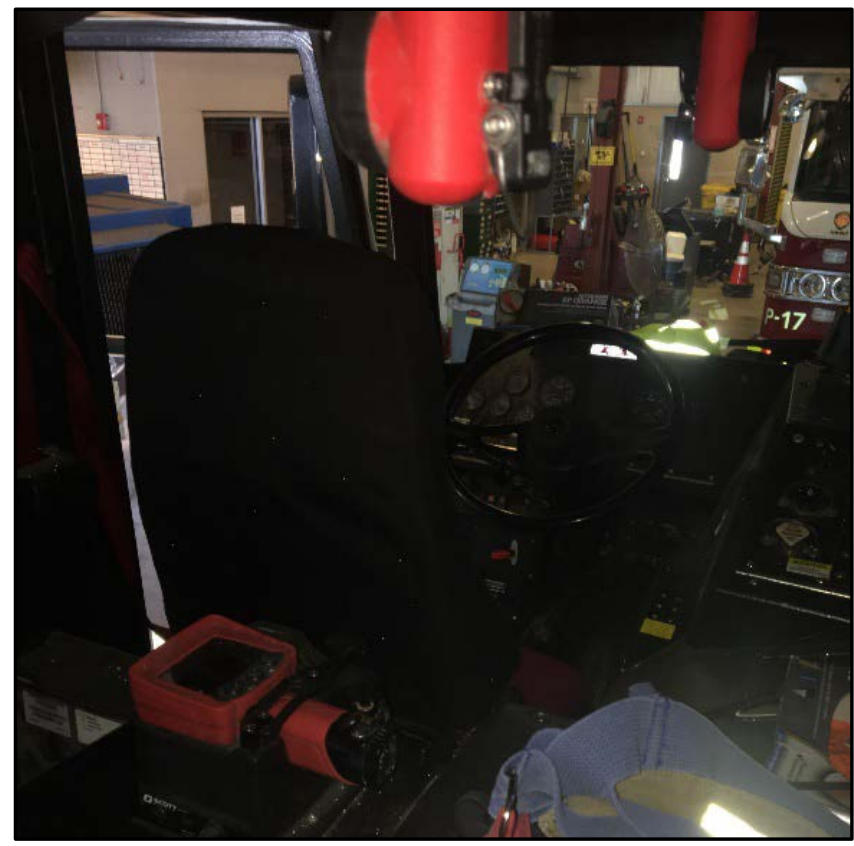

Photo 2. Station 1's usual Aerial Platform. Location of the TIC and its charger bolted to the console behind the engineer's chair. (Photo courtesy of the fire department.)

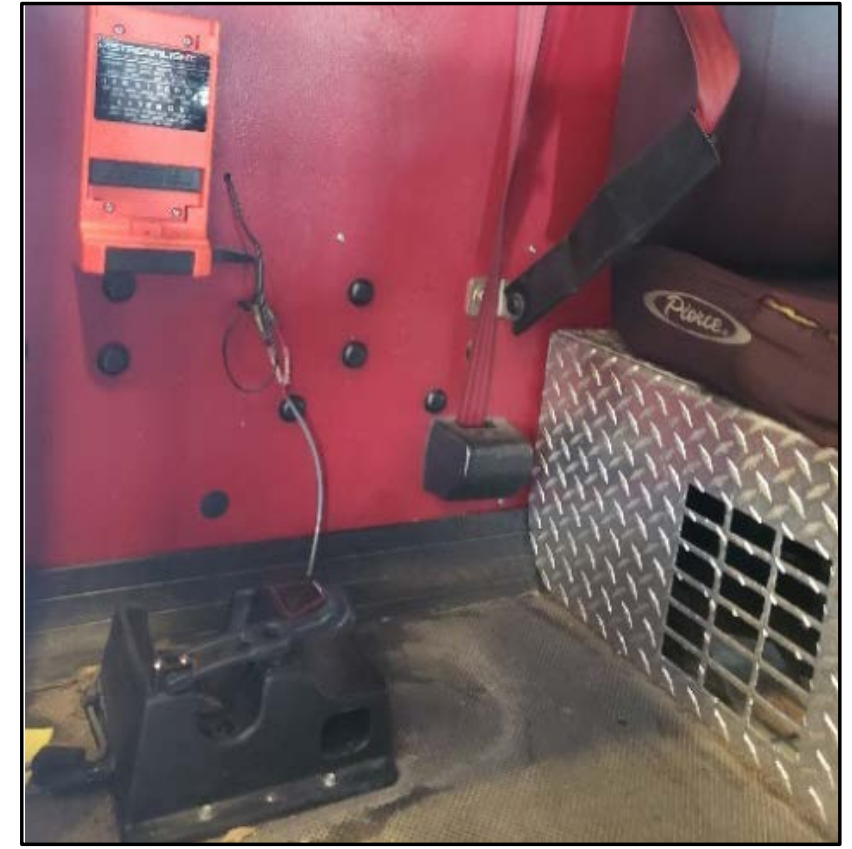

Photo 3. Aerial Platform 1 replacement apparatus. TIC charger bolted on the floor behind the officer's seat. (Photo courtesy of the fire department.) 


\section{While Maneuvering Outside His Apparatus, Firefighter Falls into Roadway and Is Struck and Killed by a Delivery Van - Texas}

The exterior lighting on the replacement Aerial Platform 1's cab consisted of high and low beam incandescent headlights, light emitting diode (LED) emergency lights above the headlights, two LED light bars on the cab's roof over the engineer's and officer's seat, and small, yellow cab/trailer marker lights. A master emergency light switch turns on flashing: 1) high beam headlights, 2) red and blue emergency lights, and 3) red light bars. When the apparatus is put into park, the flashing high beams automatically revert to non-flashing low beams. Aerial Platform 1 carries five traffic cones and a box of flares as traffic warning devices. It also carries four high visibility traffic safety vests compliant with NFPA 1500 [NFPA 2018a].

Per the fire department's standard operating procedures for responses to smoke with an odor, a single engine, Engine 1, was dispatched. Engine 1 was staffed by a lieutenant, engineer, and two firefighters. After searching for the source of the smoke for about 20 minutes, Engine 1's officer requested dispatch for a ladder truck to assist in locating the source of the smoke and for the use of electric fans for ventilation. Although Aerial Platform 11 was initially assigned the call, dispatch cancelled Aerial Platform 11 and re-assigned the call to Aerial Platform 1 shortly after Aerial Platform 1 returned to quarters from a medical call. Aerial Platform 1 was staffed by a captain (right front seat), an engineer (left front seat), and two firefighters in the back seat. While responding to this incident, the firefighterparamedic sat behind the captain on the passenger side of the apparatus.

The firefighter-paramedic was working his normal 24-hour shift (0900 hours to 0900 hours), at his normal station (Station 1), with his usual crew (A shift). Aerial Platform 1 was nearing the end of their 24-hour shift when the call was received. The crew had responded to seven previous calls over the course of their shift, the last being a medical call at 0639 hours before returning to their station at 0701 hours. During his shift, the victim was also assigned to Station 1's squad. The squad apparatus responds to non-emergency calls and is staffed by one firefighter from Aerial Platform 1 (the firefighter-paramedic) and one firefighter from Engine 1. During their shift, the squad responded to two calls (two medical calls lasting less than 30 minutes each), and a single training exercise lasting four hours and 49 minutes which ended just before midnight. The firefighter-paramedic had not worked any overtime shifts the week prior to this incident.

The commercial delivery van that struck the firefighter-paramedic was a 2014 Ford Econoline.

\section{Timeline}

This summary timeline outlines the sequence of events in which a 49-year-old male career firefighterparamedic died. Not all incident events are included. The times are approximate and were obtained by studying the dispatch records, audio recordings, witness statements, security camera footage, and forensic evidence, courtesy of the local fire and police departments. 


\section{While Maneuvering Outside His Apparatus, Firefighter Falls into Roadway and Is Struck and Killed by a Delivery Van - Texas}

\section{Dispatch Communications and Fire Department Response}

Hotel employee calls 911 for light grey smoke and burnt plastic odor in the hotel lobby.

Engine 1 dispatched.

Engine 1 en route.

Engine 1 arrives at the five-story hotel.
Time

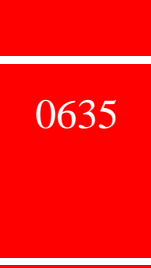

0636

0638

0641

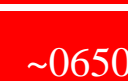

$\sim 0650$

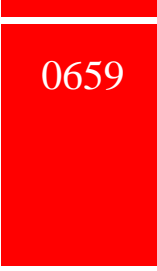

0701

Aerial Platform 11 dispatched to assist Engine 1.

Aerial Platform 1 returns from medical call.

Aerial Platform 11 en route.

Dispatch cancels Aerial Platform 11 which returns to their station.

Aerial Platform 1 dispatched to assist Engine 1.

Aerial Platform 1 en route.

Aerial Platform 1 arrives.

Engine 1 officer requests ladder investigation and for electric ventilation fans.

0701

\section{3}

0704

0704

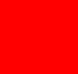

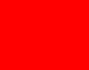
0708
Fireground Communications and Fireground Operations

Smoke and odor confirmed.

Firefighters search for source.

Hotel lobby doors are opened to dissipate smoke/odor.

Aerial Platform 1 parks in the southbound lane of a two-lane roadway. 


\section{While Maneuvering Outside His Apparatus, Firefighter Falls into Roadway and Is Struck and Killed by a Delivery Van - Texas}

\section{Dispatch Communications and Fire Department Response}

Engine 1 engineer-paramedic requests medic unit for a firefighter down.

Medic 5 dispatched and en route.

Engine 1 officer requests dispatch for additional crews to take over smoke investigation.
Time

0711

0711

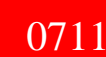

0712 breathing but has carotid pulse.

Engine 1 engineer-paramedic requests Aerial Platform 1 officer and crew leave the hotel lobby and go outside to assist Aerial Platform 1 firefighter-paramedic

0713

Paramedics from Engine 1 and Aerial Platform 1 begin advance life support measures including cardiac monitoring, intubation, cardiopulmonary resuscitation (CPR), and intraosseous access.

Engine 3 dispatched.

Aerial Platform 11 dispatched and en route.

Engine 1 officer asks if the battalion chief and medic officer are en route.

Engine 3 en route.

Medic 6 dispatched and en route. 


\section{While Maneuvering Outside His Apparatus, Firefighter Falls into Roadway and Is Struck and Killed by a Delivery Van - Texas}

\section{Dispatch Communications and Fire Department Response}

Engine 3 and Medic 6 arrive on scene.

Police dispatched to scene.

Medic 5, Aerial Platform 11, and Medic Officer 4 arrive.

Medic 5 departs for trauma center.

Medic 5 arrives at trauma center.

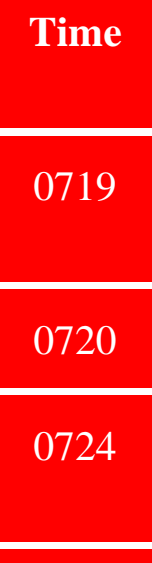

0727

0732

\section{4}

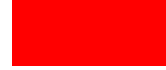

\section{0}

Firefighter-paramedic pronounced deceased in the trauma center's emergency department.

Aerial Platform 11 crew found burned-out air conditioner motor on the street level most likely responsible for the smoke and odor. Power supply to the air conditioner shut off.

\section{Personal Protective Equipment}

At the time of the incident, the firefighter-paramedic was wearing his station uniform (navy blue pants, navy blue shirt, and station boots). The firefighter-paramedic's station boots were the 5.11 tactical 8inch side-zip duty boots (see Photo 4). 


\section{While Maneuvering Outside His Apparatus, Firefighter Falls into Roadway and Is Struck and Killed by a Delivery Van - Texas}

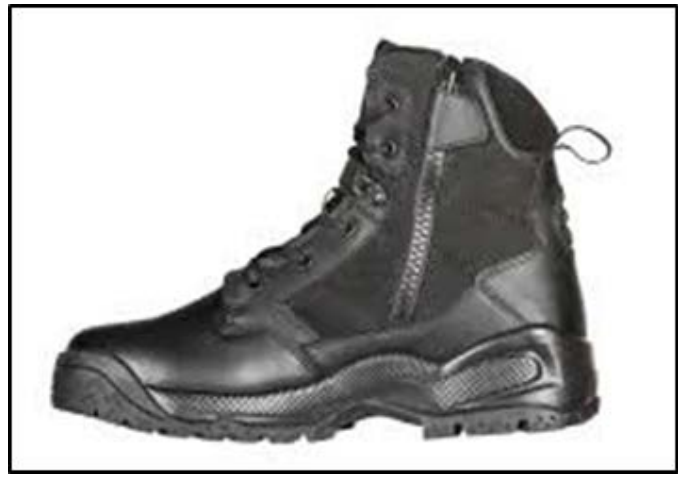

Some firefighters leave the side zipper open to facilitate boot removal when responding to a fire emergency requiring the use of bunker boots. According to his crew members, the firefighter-paramedic frequently kept his boots in the unzipped position. During this incident, the firefighter-paramedic's turnout pants, coat, and bunker boots were in the rear cab of the apparatus covering the TIC charging in its docking station located on the floor of the rear seat behind the officer (see Photo 5).

\section{Weather and Road Conditions}

At 0711 hours on October 15, 2019, the temperature was 77 degrees Fahrenheit, the relative humidity was $84 \%$, with a 14 mile per hour wind out of the south. The skies were cloudy with no precipitation over the proceeding 24 hours [Weather Underground 2019].

The incident occurred on a two-lane road traveling north and south divided by a double yellow line. The asphalt roadway surface was dry when the incident occurred. The roadway had no shoulder. There was a 3-foot concrete sidewalk adjacent to the curb. The unposted speed limit was $30 \mathrm{mph}$. Visibility was poor due to the time of day (12 minutes before sunrise), dim and widely spaced streetlights, and Aerial Platform 1's emergency lights.

\section{Investigation}

On October 15, 2019, at 0636 hours Engine 1 was dispatched for a report of a light smoke and a burnt plastic odor in the lobby of a hotel. Engine 1 arrived on-scene at 0641 hours and parked in the hotel's parking lot facing the lobby. Dressed in their turnout pants and boots, the crew of four met the hotel manager in the lobby to investigate. 


\section{While Maneuvering Outside His Apparatus, Firefighter Falls into Roadway and Is Struck and Killed by a Delivery Van - Texas}

A light grey haze was noted with an electrical/mechanical odor in the lobby. Thinking the source might be an air conditioning unit on the roof, the two firefighters were led to the fifth (top) floor by hotel maintenance. One firefighter climbed a ladder into the attic with Engine 1's TIC. Not finding any smoke or heat signatures with the TIC, the firefighter exited the attic. The two firefighters and the hotel maintenance made their way down to the lobby, checking each floor along the way for any smoke or odor.

The two firefighters reported their lack of findings to their Engine 1's lieutenant (the Incident Commander for the response) in the lobby. The Incident Commander assigned the engineer and two firefighters to: 1) open the lobby's east and west doors to help clear the smoke/odor, and 2) locate and evaluate the air conditioning units on the street level. Shortly thereafter, the Incident Commander requested dispatch for a ladder company to: 1) assist with locating the source of the smoke/odor, and 2) utilize the unit's large electrical fans to quickly dissipate the smoke/odor for the comfort of the hotel clients who were beginning to gather in the lobby for breakfast.

Although this call was within Station 1's jurisdiction, Aerial Platform 1 was responding to an earlier medical call. Thus, Aerial Platform 11 was dispatched to assist Engine 1 at 0701 hours. Just as Aerial Platform 11 was en route, Aerial Platform 1 returned to quarters. After checking with Aerial Platform 1, dispatch cancelled Aerial Platform 11 and assigned Aerial Platform 1 to the call at 0704 hours. Aerial Platform 1 arrived on-scene at 0708 hours and parked in the southbound lane of a two-lane roadway.

All four crew members of Aerial Platform 1 gathered at the rear of the truck to unpack the electrical ventilation fans and electric cords. All were wearing their station uniforms, but not reflective vests. As the crew of Aerial Platform 1 began to make their way toward the hotel, the captain asked the firefighter-paramedic to retrieve the TIC from their apparatus.

Presumably, the firefighter-paramedic could not see the TIC behind the officer's seat because it was covered by his turnout gear (see Photo 5). In addition, the firefighter-paramedic had become accustomed to the TIC charger location on the console behind the engineer's seat. At approximately 0711 hours, the firefighter-paramedic was near the engineer's door of Aerial Platform 1, most likely thinking that the TIC was behind the engineer's seat. At the same time, a delivery van was traveling northbound at about 30 miles per hour (mph), the unposted speed limit. Visibility was poor due to the time of day (12 minutes before sunrise), dim and widely spaced streetlights, Aerial Platform 1's flashing emergency lights, and its low beam headlights.

Just as the van reached the front end of Aerial Platform 1, the firefighter-paramedic fell backwards into the northbound lane perpendicular to the engineer's door. It is unclear if he was about to enter the cab or had just exited the cab. It is also unclear whether the firefighter-paramedic slipped or tripped. The delivery van struck the firefighter-paramedic, dragging him 26.5 feet before his body was released from the underside of the van (see Diagram 1). The firefighter-paramedic's left station boot was found under Aerial Platform 1's rear cab door, approximately 14 feet away from his final resting area. The right boot was found close to the telephone pole on the northbound right curb, approximately 18 feet 


\section{While Maneuvering Outside His Apparatus, Firefighter Falls into Roadway and Is Struck and Killed by a Delivery Van - Texas}

away from his final resting area (see Diagram 1). After initially accelerating, the driver slammed on the brakes, exited the vehicle, and screamed for help.

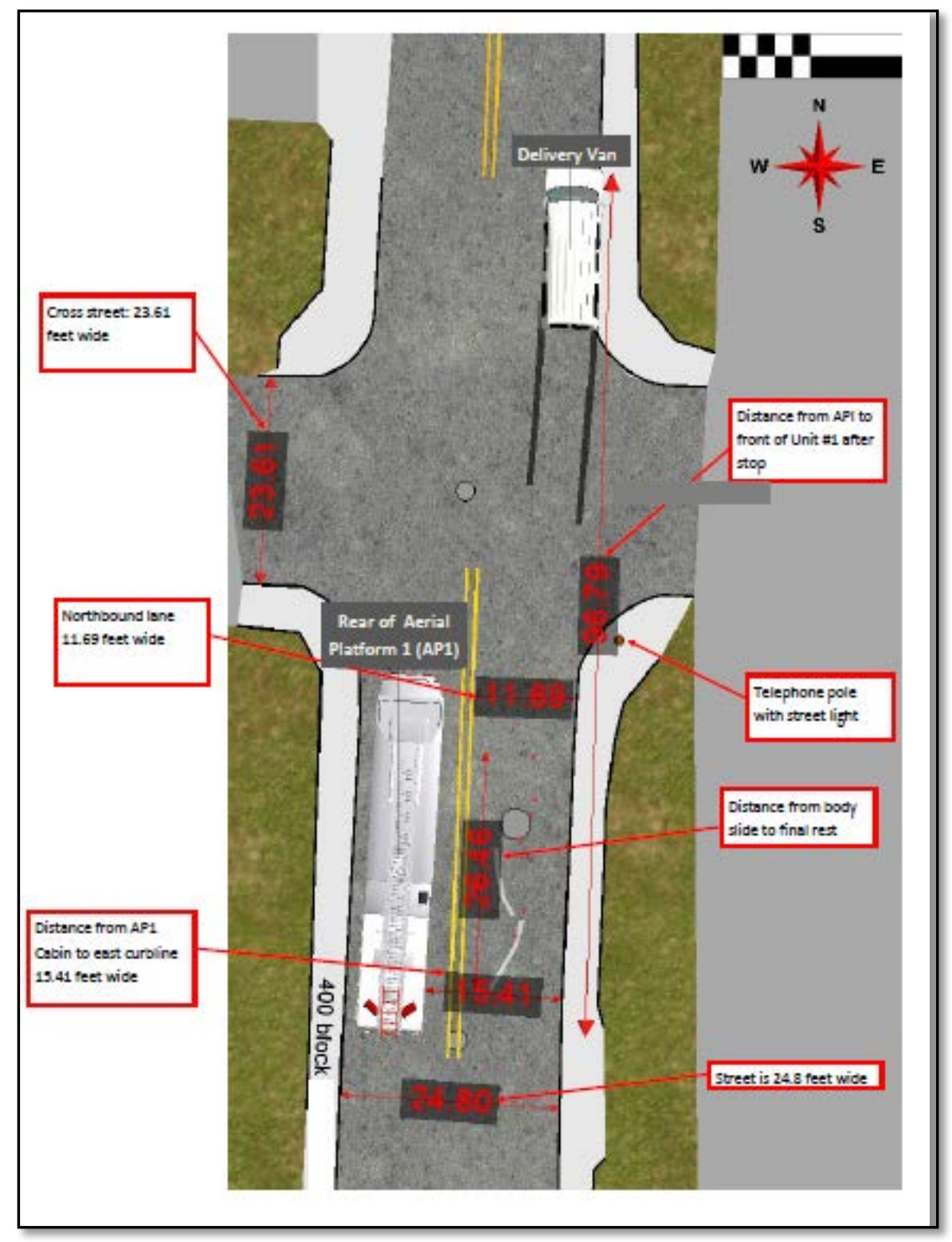

Diagram 1. Street widths and distances between the parked Aerial Platform 1 in the southbound lane and the stopped delivery van in the northbound lane. The firefighterparamedic was dragged 26 feet under the delivery van before being released to the final resting location.

(Diagram courtesy of the fire department with NIOSH edits.) 


\section{While Maneuvering Outside His Apparatus, Firefighter Falls into Roadway and Is Struck and Killed by a Delivery Van - Texas}

The engineer-paramedic and firefighter from Engine 1 were the first to respond. They found the Aerial Platform 1's firefighter-paramedic unconscious, not breathing with severe trauma to his head and chest area and a questionable carotid pulse. The engineer-paramedic radioed dispatch requesting medic units for a firefighter down as he retrieved the medical bag from Aerial Platform 1. Engine 1 firefighter notified his officer of the situation as Engine 1's engineer-paramedic requested Aerial Platform 1 officer and crew exit the hotel and come outside to assist the Aerial Platform 1 firefighter-paramedic who was struck by the passing vehicle.

At 0712 hours Medic 5 was dispatched and en route. The engineer-paramedic from Engine 1 prepared to intubate the firefighter-paramedic as the Engine 1 firefighter applied the cardiac monitor pads. The firefighter-paramedic's heart rhythm was pulseless electric activity. As the medic units arrived, advanced life support measures continued, including cardiac monitoring, intubation, CPR and whole blood transfusion via the intraosseous route. Medic 5 departed for the local hospital's trauma center at 0727 hours with CPR in progress. Despite the heroic medical care in the field and in the trauma center, the firefighter-paramedic was pronounced dead in the trauma center's emergency department at 0804 hours. Additional medic units evaluated and treated the driver of the delivery van who was extremely distraught over the incident. The police did not cite or ticket the driver, and the district attorney's office did not file charges.

At 0713 hours, Engine 1 officer requested dispatch for additional crews to take over the smoke investigation, and Engine 3 and Aerial Platform 11 were dispatched. Sometime after noon, Aerial Platform 11 crew found a burned-out air conditioner motor located on the street level considered most likely responsible for the smoke and odor. Power supply to the air conditioner was shut off and the last units cleared the scene at 1256 hours.

\section{Contributing Factors}

Occupational injuries and fatalities are often the result of one or more contributing factors or key events in a larger sequence of events that ultimately result in the injury or fatality. NIOSH investigators identified the following items as key contributing factors in this incident that ultimately led to the fatalities:

- Lack of traffic incident management

- Lack of reflective vests worn by firefighters over their station uniforms

- Lack of a temporary traffic control (TTC) plan

- Poor visibility

- The firefighter-paramedic's station boots may have been unzipped, presenting a slip/trip hazard

- The firefighter-paramedic may not have used three points of contact for access to/egress from the apparatus

- Use of a replacement apparatus, resulting in the firefighter-paramedic not being familiar with the TIC charging/storage location. 


\section{While Maneuvering Outside His Apparatus, Firefighter Falls into Roadway and Is Struck and Killed by a Delivery Van - Texas}

\section{Cause of Death}

An autopsy was performed by the deputy medical examiner. The County Medical Examiner's office concluded the firefighter-paramedic "died as a result of blunt force injuries reportedly sustained as a pedestrian struck by a motor vehicle.”

\section{Discussion}

Vehicle-related firefighter deaths consistently account for the second-largest share of line-of-duty deaths [Fahy et al. 2007; Fahy \& Molis 2019]. These vehicle-related deaths are divided into crashes and struck-by incidents, with crashes representing $81 \%$ of the vehicle-related deaths and struck-by the remaining 19\% [USFA 2014].

\section{Roadway Crash Deaths}

In the mid-to-late 2000's, multiple fire service organizations developed, implemented, and publicized prevention programs to address firefighter roadway crash deaths [Dickinson 2007, ESRI/CVVFA 2019, IAFC 2009, IAFF 2019, IFSTI 2005, NFFF 2007, NFPA 1999, 2016, 2017, 2018a, 2018b, 2019b, NVFC 2016, USFA 2014]. These programs included policies and procedures for vehicle safety, safety belt use, driver training, and driver qualifications, and had impressive results. During the 10year period from 2001 to 2010, there was an average of 15 roadway vehicle crash deaths per year [Fahy et al. 2012]. Following implementation of the prevention programs, roadway vehicle crash deaths were reduced by $28 \%$ to 10.8 per year for the 5-year period from 2014 to 2018 (see Table 1) [Hales 2019].

Table 1. Number and Type of Vehicle-Related Firefighter Fatalities by Year, 2014-2018

\begin{tabular}{|l|l|l|l|l|l|l|l|}
\hline & 2014 & 2015 & 2016 & 2017 & 2018 & Total & $\begin{array}{l}\text { Five-Year } \\
\text { Average }\end{array}$ \\
\hline Struck-by Vehicle & 3 & 5 & 2 & 10 & 4 & $24(31 \%)$ & 4.8/year \\
\hline Vehicle Crashes & 9 & 8 & 17 & 8 & 12 & $54(69 \%)$ & $10.8 /$ year \\
\hline Total Vehicle-Related Deaths & 12 & 13 & 19 & 18 & 16 & $78(100 \%)$ & $15.6 /$ year \\
\hline
\end{tabular}

Source: NFPA

\section{Roadway Struck-by Vehicle Deaths}

In addition to addressing the firefighter roadway vehicle crash deaths, the fire service organizations listed above joined other first responder organizations (e.g., International Association of Chiefs of Police (IACP), National Law Enforcement Officers Memorial Fund (NLEOMF)) and public safety organizations, including: the Federal Highway Administration (FHWA), National Institute of Standards \& Technology (NIST), National Safety Council (NSC), US Department of Transportation (DOT)/National Highway Traffic Safety Administration (NHTSA), and the US DOT Intelligent Transportation Systems (ITS) Joint Program Office to address the problem of roadway stuck-by vehicle deaths [ESRI and CVVFA 2019]. These organizations conducted research, developed guidelines, conducted training, and lobbied for laws addressing effective traffic control and management during emergency operations. The major components of these efforts include:

- Conducting pre-incident planning 


\section{While Maneuvering Outside His Apparatus, Firefighter Falls into Roadway and Is Struck and Killed by a Delivery Van - Texas}

- Developing traffic incident management (TIM) SOPs

- Training first responders in TIM

- Using the apparatus as a blocking device

- Using warning devices (e.g., cones, flares)

- Wearing high visibility apparel

- Adopting move over and slow down laws

- Educating the public about these laws and the risks faced by first responders working on the roadside.

Unfortunately, despite the impressive work of these organizations, individuals, and programs, the number of roadway struck-by vehicle deaths among firefighters have not gone down. For the 14-year period from 2000 to 2013, the roadway struck-by vehicle deaths averaged 4.3 firefighter deaths per year [Fahy 2014]. For the five-year period from 2014 to 2018, these deaths increased by $12 \%$ to an average of 4.8 firefighter deaths per year [Hales 2019] (see Table 1).

The following recommendations highlight and expand upon the previous efforts by first responder organizations to address the safety risks associated with working on, or near, roadways, particularly as they apply to apparatuses parked on commercial and residential streets.

\section{Recommendations}

Recommendation \#1: Fire departments should train firefighters, especially firefighters in the jump seats, to exit and enter the apparatus from the side not facing oncoming or approaching traffic.

Discussion: Fire departments should modify their roadside safety SOPs and standard operating guidelines (SOG) to include fire apparatuses parked or staged on two-lane commercial or residential streets. Fire departments should then educate and train firefighters on this updated policy/procedure.

Chapter 9 of NFPA 1500 addresses traffic incident management consistent with other first responder organizations. The standard requires departments to "establish, implement, and enforce SOP regarding emergency operations involving traffic” [NFPA 2018a]. While the chapter is directed toward units responding to roadway vehicle fires or crashes, it is also relevant to apparatus parking or staging on municipal streets because it exposes department personnel to traffic.

The fire department in this incident had a roadside safety SOG consistent with NFPA 1500. As stated in their SOG, "It is the goal of the [redacted] fire department to provide a safe working environment for all personnel. 'This guideline will assist in identifying hazards and employing safe work practices while operating at an emergency scene where traffic is a potential or actual hazard [NFPA 2018a]."” This clause, “...where traffic is a potential or actual hazard...” clearly indicates their roadside safety SOG applies to commercial or residential streets because firefighters are exposed to moving traffic at these locations.

Unfortunately, many firefighters do not apply roadside safety principles when their apparatus is parked on commercial or residential streets even though $41 \%$ of roadway responses are on commercial 


\section{While Maneuvering Outside His Apparatus, Firefighter Falls into Roadway and Is Struck and Killed by a Delivery Van - Texas}

streets/residential streets/parking lots, while only 27\% are on highways [Aherns \& Evarts 2017]. Although highway and freeway speeds are higher, the safety hazards of getting in, getting out, and getting around the apparatus on commercial and residential streets are still present. An Ohio State Highway Patrol study found that $40 \%$ of officer struck-by incidents occurred on non-interstate roadways [OSHP 2006]. The fire department in this incident currently requires online TIM training, but the fire department does not have records of the firefighter-paramedic completing that training. In 2006, the firefighter-paramedic completed an eight-hour in-class "traffic scene safety and hands-on extrication” training course at the Texas Engineering Extension Service (TEEX) at Texas A\&M University.

In this incident, the Aerial Platform 1 engineer appropriately parked his apparatus on the southbound roadway given the lack of space in the hotel's parking lot, the number of parked cars on the side street, and proximity to the hotel. Once a decision to park Aerial Platform 1 on the roadway was made, the fire department's roadside safety SOG should have been followed. This point could be emphasized during required annual training on TIM for all firefighters and officers.

\section{Recommendation \#2: When not wearing turnout gear, fire departments should ensure firefighters wear reflective traffic safety vests whenever parking, working on, or crossing a roadway.}

Discussion: Federal law requires anyone working on a roadway to wear an ANSI 107-2004 or ANSI 207-2006 compliant high-visibility vest [FHWA 2009a]. An exemption was created for firefighters and others wearing turn-out gear while engaged on roadways. NFPA now has similar requirements that did not exist in the 2003 edition of NFPA 1901. NFPA 1500, 9.4.9, states, "When member assignments place them in potential conflict with motor vehicle traffic, they shall wear a high-visibility garment that meets ANSI 107, American National Standard for High-Visibility Apparel and Access, unless exposed to fire, heat, flame, or hazardous materials where NFPA-compliant turnout gear is more appropriate" [NFPA 2018a]. NPFA 1901, 5.9.4(18), states “one traffic vest for each seating position, each vest to comply with ANSI/ISEA 207, Standard for High-Visibility Public Safety Vests, and have a five-point breakaway feature that includes two at the shoulders, two at the sides, and one at the front” [NFPA 2016].

In this incident, the department's roadside safety SOG addresses the use of traffic vests in two sections. In the general guidelines (.03) it states, "During active firefighting, traffic vests will not be worn by those wearing a SCBA. Traffic safety vests will be worn by all personnel on scene at all other times." In the incident command guidelines (.06) it states, "Ensure all workers not involved in actual firefighting are wearing their safety vests." Given that Aerial Platform $1 \mathrm{crew}$ were in their station uniforms and not involved in firefighting, the use of traffic vests would have been appropriate.

\section{Recommendation \#3: Fire departments should establish a TTC zone when apparatuses are parked or staged on two-lane commercial or residential streets.}

Discussion: Federal law requires a TTC plan to facilitate road use through an incident area [FHWA 2009b]. When traffic in both directions must use a single lane for a limited distance, a flagger, flag transfer, pilot car, stop/yield control, or traffic control signals should facilitate one-way movement 


\section{While Maneuvering Outside His Apparatus, Firefighter Falls into Roadway and Is Struck and Killed by a Delivery Van - Texas}

through the constricted section [FHWA 2009c]. However, traffic through a one-lane, two-way constriction may be self-regulated when:

1) the street is low volume,

2) the work area is short, and

3) road users from both directions can see the traffic approaching from the opposite direction through and beyond the worksite [FHWA 2009c].

As part of a TTC plan, there should be an advance warning area in which road users are informed about an upcoming incident area. For fire apparatuses parking and staging on residential and commercial roads, the use of cones and/or flares should suffice. NFPA 1500, 9.3, states “...warning devices shall be placed to provide a safe work zone as well as early warning to the motoring public ..." while paragraph 9.4.5 states, "The following warning devices shall be used to warn oncoming traffic of the emergency operations and the hazards to member(s) operating at the incident:

- A minimum of 5 (five) 28 in or greater (71 cm or greater) fluorescent orange traffic cones with double reflective markings that are compliant with the [manual on uniform traffic control devices] MUTCD.

- Retro-reflective warning signs compliant with the MUTCD [NFPA 2018a].

Both the MUTCD and the Emergency Responder Safety Institute (ERSI) provide specifics for the placement and spacing of warning signs [ERSI 2009; FHWA 2009c]. A short taper having a minimum length of 50 feet and a maximum length of 100 feet with channelizing devices at approximately 20foot spacing should be used to guide traffic into the one-lane section, and a downstream taper with a length of 100 feet should be used to guide traffic back into their original lane [FHWA 2009c].

The department's roadside safety SOG addresses the use of cones/warning devises in three sections [general guidelines (.03), apparatus and emergency vehicle parking guidelines (.04), and the incident command guidelines (.06)]. The general and parking guidelines recommend establishing advance warning and adequate traffic control measures upstream of the incident to reduce travel speeds. For slower moving traffic, traffic cones should be deployed at 25-foot tapered intervals upstream of the blocking apparatus with the furthest traffic cone approximately 100 feet upstream. The incident command guideline states, “Designate a crewmember to deploy traffic warning devices.” The SOG does not address downstream warning devices to warn approaching motorists coming from the opposite (downstream) direction. While this would not be important on a divided highway or a 4-lane roadway, it would be important in this incident where two-way traffic was constricted into one lane. The Aerial Platform 1 carried five cones and a box of flares as warning devices. Although Aerial Platform 1 would not have had enough traffic cones to use on the downstream direction, additional cones could have been retrieved from Engine 1.

In this incident, the conditions for self-regulation of one-lane two-way traffic were met. However, other than apparatus emergency lights, there was no additional warning to direct motorists around the apparatus parked in their lane. Although there was minimal traffic at the time of this incident (0700 hours), tapered traffic cones in both the advanced warning/transition areas and the termination area would have been appropriate [NFWA 2009c]. The local police department can assist with deploying these assets. 


\title{
While Maneuvering Outside His Apparatus, Firefighter Falls into Roadway and Is Struck and Killed by a Delivery Van - Texas
}

\author{
Recommendation \#4: Once TTC measures are in place, fire departments should consider \\ implementing procedures to turn off the apparatus headlights and reduce the flashing frequency of \\ the emergency lights, particularly during the dark hours (dusk, night, dawn).
}

Discussion: For the safety of emergency responders, use of emergency-vehicle lighting (such as highintensity rotating, flashing, oscillating, or strobe lights) during the initial stages of a traffic incident is essential. While emergency-vehicle lighting provides an effective warning, it does not provide traffic control [FHWA 2009d]. In addition, too many lights at an incident scene can be distracting and confusing for approaching road users, especially when it is dark. Once good traffic control has been established (e.g., advanced warning signs and traffic control devices to slow, divert or detour traffic), the use of emergency-vehicle lighting can be reduced [FHWA 2009d].

Public safety agencies should examine their policies on the use of emergency-vehicle lighting, especially after a traffic incident scene is secured, with the intention to safely reduce the lighting. Because the glare from floodlights or vehicle headlights can impair the nighttime vision of approaching road users, any floodlights or vehicle headlights that are not needed for illumination, or to provide notice to other road users of an incident response vehicle being in an unexpected location, should be turned off at night [FHWA 2009d].

NFPA 1500 also addresses this topic in 9.4.2 and 9.4.3. These paragraphs state, "When a temporary TIMA [traffic incident management area] has been established, the apparatus in the blocking position shall reduce warning lighting" and "All additional responding vehicles, when arriving on the scene, shall be positioned downstream from the blocking vehicle with warning lighting reduced....” [NFPA 2018a].

The guidelines of the department's roadside safety SOG states, "Reduce all sources of vision impairment to approaching motorists at nighttime incidents including vehicle headlights, wigwags, and all unnecessary lighting." The incident command guidelines (.06) states, "Command shall assure that Opticom strobe systems are turned OFF along with all unnecessary emergency lighting. At night time when using scene lights, make sure the lighting will not blind the approaching motorist. Make sure directional arrow light, if equipped, is pointing in the correct direction.”

The Aerial Platform 1 replacement apparatus has a lighting reduction feature that, when in park, the headlights are automatically lowered to low beams and stop flashing. However, the other emergency lighting continues to flash at the same frequency.

In this incident, given the lack of TTC for oncoming motorists, the continued use of the emergency lights to warn approaching motorists was appropriate. However, continued use of the low beam headlights may have impaired the approaching driver's vision. Fire departments should consider revising roadside safety SOGs to include a provision for turning off the headlights and manually slowing the emergency flashing frequency when appropriate TTC measures are in place. 


\title{
While Maneuvering Outside His Apparatus, Firefighter Falls into Roadway and Is Struck and Killed by a Delivery Van - Texas
}

\author{
Recommendation \#5: Fire departments, along with their state and local partners, should consider a \\ public education campaign on the state laws regarding speed limits around emergency operations, \\ and the enforcement of those laws.
}

Discussion: The general public lacks an understanding of the safety hazards confronting first responders engaged in roadway incidents and is often unaware of laws regulating their driving behavior at these incidents [Extreme Tactical Dynamics 2020]. All 50 states have passed some version of “Slow Down, Move Over" laws [Extreme Tactical Dynamics 2020]. These laws require motorists traveling on multi-lane roadways to, when practical, merge away from a vehicle working on the side of the highway to provide an empty travel lane of safety for the worker. If not practical (either due to traffic volume or road design), the motorist must slow significantly below the posted speed limit while passing the roadside worker.

Texas' law, passed in 2003, states:

On approaching a stationary authorized emergency vehicle using visual signals that meet the requirements of Sections 547.305 and 547.702, an operator, unless otherwise directed by a police officer, shall:

(1) vacate the lane closest to the emergency vehicle when driving on a highway with two or more lanes travelling in the direction of the emergency vehicle; or

(2) slow to a speed not to exceed:

(A) 20 miles per hour less than the posted speed limit when the posted speed limit is 25 miles per hour or more; or

(B) 5 miles per hour when the posted speed limit is less than 25 miles per hour [Texas Transportation Code 2016].

In this incident, the delivery van approached Aerial Platform 1 at approximately $30 \mathrm{mph}$. If the driver had been abiding by Texas law, he would have been travelling at $10 \mathrm{mph}$. Given that the firefighterparamedic suddenly fell into the northbound lane, it is unclear if speed reduction would have allowed the driver to swerve or stop before striking the firefighter-paramedic. However, a lower speed may have reduced the risk of injury to the firefighter-paramedic.

To make motorists aware of the current Texas law, NIOSH encourages the fire department's public information office, perhaps in conjunction with law enforcement agencies, issue a series of public education campaigns on this topic. The ERSI had developed multiple public service announcements, available in print, broadcast, and social media, that could be used directly or modified for use by the Public Information Officer (see Appendix 1) [ESRI 2019b].

Recommendation \#6: To reduce the risk of slips, trips, or falls, fire departments should encourage firefighters to lace-up or zip-up their station boots.

Discussion: According to the NFPA, slips/trips/fall/jumps causes 18\% of firefighter injuries [Campbell, Evarts, Molis 2019]. While loose fitting shoes (or untied laces or unzipped) are reported to increase the risk of a slip, trip, and fall, we were unable to find any confirming studies. The firefighterparamedic's crew noted he frequently walked around the station with his boots unzipped. 


\section{While Maneuvering Outside His Apparatus, Firefighter Falls into Roadway and Is Struck and Killed by a Delivery Van - Texas}

In this incident, the firefighter-paramedic was stuck and dragged, and his boots ended up a significant distance from his final position. This finding suggests his boots may have been unzipped before impact. If his boots were unzipped, it may have initiated his slip/trip and backwards fall into the southbound lane. However, all of this is conjecture. Although there is no evidence that following this recommendation would have prevented this fatality, ensuring all staff lace-up or zip-up their station boots during work hours is a reasonable preventative action.

Recommendation \#7: To reduce the risk of slips, trips, or falls during access to, or egress from, the apparatus, fire departments should train firefighters to use three points of contact.

Discussion: Climbing into and out of apparatuses presents a risk for slips, trips, and falls. Bunker boots and the urgency of emergency response make this a frequent and serious risk for firefighters, particularly when exiting the cab on a roadway with moving traffic. The three-point technique is a simple and effective way to minimize this risk [AMI Environmental 2012; Lehtola et al. 2001; NFPA 2016]. This technique involves keeping three limbs in contact with the apparatus when climbing into, or out of, the cab. This could be two hands and one foot, or two feet and one hand. This technique dictates that the firefighter be facing the equipment; you cannot have three points of contact if you are jumping off or sliding out of the seat. This technique also necessitates any needed cab equipment be placed on the seat or the floor of the cab before entering or exiting the apparatus.

\section{Recommendation \#8: Fire departments should ensure firefighters familiarize themselves with equipment locations when a replacement apparatus is being used.}

Discussion: To improve efficiency during a response, firefighters should be aware of the location of all equipment on their apparatus. This is not a problem for firefighters responding in their usual apparatus. However, when a replacement apparatus is being used for the first time, as in this incident, firefighters may be unfamiliar with some of the equipment locations. Thus, firefighters should familiarize themselves with the storage location of various equipment at the beginning of their shift.

In this incident, the Aerial Platform apparatus Station 1 had been using over the past several months had its TIC's charging station mounted on the console behind the engineer's seat. On Oct. 13, 2019, Aerial Platform 1 was scheduled for maintenance and replaced by an apparatus of the same make and model. However, the replacement Aerial Platform had its TIC charging station bolted onto the floor behind the officer's seat. Perhaps, if the firefighter-paramedic had known of this location, he would have remained on the side of the apparatus that was opposite from moving traffic.

\section{Recommendation 9: \#Fire departments should consider installing retroreflective markings on the interior cab doors of all apparatuses.}

Discussion: Although this recommendation would not have prevented this fatality, it is being provided to reduce the risk of stuck-by incidents along roadways among first responders (fire, police, EMS), Department of Transportation roadway crews, and towing services. Both the 2003 and the 2016 editions of NPFA 1901 require the use of retroreflective material on the inside of each cab door that 


\section{While Maneuvering Outside His Apparatus, Firefighter Falls into Roadway and Is Struck and Killed by a Delivery Van - Texas}

personnel use to enter or exit the apparatus. In addition, as part of its high visibility innovations training video, the ERSI recommends retroreflective markings on the inside doors of all EMS vehicles and all other fire service apparatuses [ERSI 2020]. NPFA 1917, Standard on Automotive Ambulances, also requires retroreflective markings (e.g., chevrons, Battenberg) on the inside of all vertically hinged doors, but it does not specify that these markings be placed on the inside of the cab doors [NFPA 2019c]. High visibility retroreflective markings on the interior cab doors provide another warning system to vehicles approaching from the rear that emergency response personnel are operating in the area.

In this incident, the replacement Aerial Platform 1 did not have high visibility chevrons or other markings on the inside or edges of the cab doors. Since the delivery van was approaching from the front of Aerial Platform 1, inside cab door markings would not have been visible from the northbound direction. Nonetheless, this recommendation would help to reduce the risk of future stuck-by incidents when firefighters are exiting from their cab in traffic.

\section{References}

Aherns M, Evarts B [2017]. Fire department roadway and vehicle incidents. Quincy MA: National Fire Protection Association, http://tkolb.net/FireReports/2017/osFDRoadwayIncidents.pdf.

AMI Environmental [2012]. Three point technique to prevent slips, trips, and falls. Omaha, NE, https://amienvironmental.com/three-point-technique-to-prevent-slips-trips-falls/.

Campbell R, Evarts B, Molis JL [2019]. United States firefighter injuries - 2018. Quincy, MA:

National Fire Protection Association, https:/www.nfpa.org/-/media/Files/News-and-Research/Firestatistics-and-reports/Emergency-responders/osffinjuries.pdf.

Dickinson C [2007]. USFA challenge: Take the National Seat Belt Pledge. Fire Engineering, February 2007, https://www.fireengineering.com/articles/2007/02/usfa-challenge-take-the-national-seat-beltpledge.html.

ERSI [2009]. Model standard operating guideline (SOG) for cone, flare, or sign deployment at trafficrelated incidents. Cumberland Valley PA: Emergency Responder Safety Institute, https://www.respondersafety.com/News/Model_SOG_Available_for_Download_on_Deploying_Cones _and_Flares_at_Roadway_Incidents.aspx. Date accessed: January 6, 2020.

ESRI/CVVFA [2019]. The past, present, and future of responder safety at roadway incidents: Report of workshop proceedings. Cumberland Valley PA: Emergency Responder Safety Institute and the Cumberland Valley Volunteer Firemen's Association, https://d35c9cxlt8mg8m.cloudfront.net/Downloads/fb0d1238-ae5b-4c26-86df8833ff11a57d/1/ERSIWhitePaperFuture.pdf?response-content-disposition=attachment.

ERSI [2019a]. Responder Safety: Vehicle emergency lighting and markings. Cumberland Valley PA: Emergency Responder Safety Institute, 


\section{While Maneuvering Outside His Apparatus, Firefighter Falls into Roadway and Is Struck and Killed by a Delivery Van - Texas}

https://www.respondersafety.com/Resources/Vehicle_Emergency_Lighting_and_Markings.aspx. Date accessed: January 6, 2020.

ERSI [2019b]. PIO \& public educator engagement. Cumberland Valley, PA: Emergency Responder Safety Institute, https://www.respondersafety.com/Key-Initiatives/PIO-Public-EducatorEngagement.aspx. Date accessed: January 5, 2020.

ERSI [2020]. Responder safety: High visibility innovations. Cumberland Valley, PA: Emergency Responder Safety Institute, https://learning.respondersafety.com/Training_Programs/High_Visibility_Innovations.aspx. Date accessed: April 24, 2020.

Extreme Tactical Dynamics [2020]. State move over laws. Jupiter, FL, https://www.extremetacticaldynamics.com/knowledge-base/state-statutes/move-over-laws/. Date accessed: January 5, 2020.

Fahy RF, LeBlanc RP, Molis JL [2007]. What's changed over the past 30 years? Quincy, MA: National Fire Protection Association, https://www.volusia.org/core/fileparse.php/4613/urlt/whatschanged\%5b1\%5d.pdf.

Fahy RF, LeBlanc RP, Molis JL [2012]. Firefighter fatalities in the US - 2011. Quincy, MA: National Fire Protection Association, https://www.nfpa.org/-/media/Files/News-and-Research/Fire-statisticsand-reports/Emergency-responders/Old-FFF-and-FF-Injuries/2012FFF.ashx?la=en.

Fahy RF [2014]. U.S. firefighters killed when struck by vehicles, 2000-2013. Quincy, MA: National Fire Protection Association, https://www.nfpa.org/-/media/Files/News-and-Research/Fire-statisticsand-reports/Emergency-responders/osFFStruckByVenicles.ashx?la=en.

Fahy RF, Molis JL [2019]. Firefighter fatalities in the US - 2018. Quincy, MA: National Fire Protection Association, https://www.nfpa.org/-/media/Files/News-and-Research/Fire-statistics-andreports/Emergency-responders/osFFF.pdf.

FHWA [2009a]. Chapter 6D. Pedestrian and worker safety. Manual on uniform traffic control devices (MUTCD). 2009 ed. Washington, DC: U.S. Department of Transportation, Federal Highway Administration, https://mutcd.fhwa.dot.gov/htm/2009r1r2/part6/part6a.htm. Date accessed: January 6, 2020.

FHWA [2009b]. Chapter 6A. General. In Manual on uniform traffic control devices (MUTCD). 2009 ed. Washington, DC: U.S. Department of Transportation, Federal Highway Administration, https://mutcd.fhwa.dot.gov/htm/2009r1r2/part6/part6a.htm. Date accessed: January 6, 2020.

FHWA [2009c]. Chapter 6C. Temporary traffic control elements. In Manual on uniform traffic control devices (MUTCD). 2009 ed. Washington, DC: U.S. Department of Transportation, Federal Highway 


\section{While Maneuvering Outside His Apparatus, Firefighter Falls into Roadway and Is Struck and Killed by a Delivery Van - Texas}

Administration, https://mutcd.fhwa.dot.gov/htm/2009r1r2/part6/part6c.htm. Date accessed: January 6, 2020.

FHWA [2009d]. Chapter 6I. Control of traffic through traffic incident management areas. In Manual on uniform traffic control devices (MUTCD). 2009 ed. Washington, DC: U.S. Department of Transportation, Federal Highway Administration, https://mutcd.fhwa.dot.gov/htm/2009r1r2/part6/part6i.htm\#section6I05. Date accessed: January 6, 2020.

Hales TR [2019]. Unpublished analysis using data extracted from the NFPA Annual Reports of Firefighter Fatalities in the United States, 2014-2018.

IAFC [2009]. Guide to IAFC model policies and procedures for emergency vehicle safety. Chantilly, VA: International Association of Fire Chiefs, https://www.iafc.org/topics-andtools/resources/resource/guide-to-model-policies-and-procedures-for-emergency-vehicle-safety. Date accessed: January 2, 2020.

IAFF [2019]. Apparatus safety campaign. Washington, DC: International Association of Fire Fighters, https://www.iaff.org/apparatus-safety-campaign/. Date accessed: January 2, 2020.

IFSTI [2005]. Guidelines for highway incident scene safety and traffic control. 1st ed. Stillwater, OK: Fire Protection Publications, CD-ROM, https:/www.ifsta.org/shop/guidelines-highway-incidentscene-safety-and-traffic-control-cd/36561.

Lehtola CJ, Becker WJ, Brown CM [2001]. Preventing injures from slips, trips, and falls. Circular 869. Agricultural and Biological Engineering Department, Florida Cooperative Extension Service, Institute of Food and Agricultural Sciences, University of Florida, http://nasdonline.org/static_content/documents/211/d000006.pdf.

NFFF [2006]. About the International First Responder Seatbelt Pledge. Crofton, MD: National Fallen Firefighters Foundation, https://www.everyonegoeshome.com/seatbelts/. Date accessed: January 1, 2020.

NPFA [2003]. NPFA 1901 Standard on automotive fire apparatus. Quincy, MA: National Fire Protection Association.

NFPA [2016]. NPFA 1901 Standard on automotive fire apparatus. Quincy, MA: National Fire Protection Association.

NFPA [2017]. NFPA 1002 Standard for fire apparatus driver/operator professional qualifications. Quincy, MA: National Fire Protection Association.

NFPA [2018a]. NFPA 1500 Standard for fire department occupational safety and health program. Quincy, MA: National Fire Protection Association. 


\section{While Maneuvering Outside His Apparatus, Firefighter Falls into Roadway and Is Struck and Killed by a Delivery Van - Texas}

NFPA [2018b]. NFPA 1451 Standard for a fire service vehicle operations training program. Quincy, MA: National Fire Protection Association.

NFPA [2019a]. NFPA 1001 Standard on fire fighter professional qualifications. Quincy, MA: National Fire Protection Association.

NFPA [2019b]. NFPA 1091 Standard on traffic control incident management personnel professional qualifications. Quincy, MA: National Fire Protection Association.

NFPA [2019c]. NFPA 1917 Standard on Automotive Ambulances. Quincy, MA: National Fire Protection Association.

NVFC [2016]. Emergency vehicle safe operations for volunteer \& small combination emergency services organizations. $3^{\text {rd }}$ ed. Washington, DC: National Volunteer Fire Council, https://www.nvfc.org/wp-content/uploads/2015/09/EVSO-Guide-3rd-edition.pdf.

OSHP [2006]. Law Enforcement Stops and Safety Subcommittee: 2006 Staff Report. Columbus, OH: Ohio State Highway Patrol, http://ntimc.transportation.org/Documents/LESS_2006StaffReport.pdf.

Texas Transportation Code [2016]. Texas emergency vehicle laws, selected sections. Austin, TX: Texas Municipal League Intergovernmental Risk Pool, https://www.tmlirp.org/wpcontent/uploads/TexasEmergencyVehicleLaws.pdf.

USFA [2014]. Emergency vehicle safety initiative, FA 336. Emmitsburg, MD: Federal Emergency Management Agency, United States Fire Administration, https://www.usfa.fema.gov/downloads/pdf/publications/fa_336.pdf.

Weather Underground. Historical weather for Tuesday, October 15, 2019. The Weather Channel Interactive, Inc, https://www.wunderground.com/history. Date accessed: December 15, 2019.

\section{Investigator Information}

This incident was investigated by Thomas Hales, MD, MPH. Dr. Hales is an investigator with the Fire Fighter Fatality Investigation and Prevention Program, Surveillance and Field Investigations Branch, Division of Safety Research, NIOSH located in Morgantown, WV. An expert technical review was provided by Mike Barakey, chief of Suffolk Fire \& Rescue in Suffolk, Virginia. A technical review was also provided by the National Fire Protection Association, Public Fire Protection Division.

\section{Additional Information}

The NIOSH investigator noted the outstanding on-scene medical care provided. The rapid and comprehensive care given to the firefighter-paramedic provided him every possible opportunity to survive this tragic event. 


\title{
While Maneuvering Outside His Apparatus, Firefighter Falls into Roadway and Is Struck and Killed by a Delivery Van - Texas
}

\section{Sources on Safety While Working Along Roadways}

\section{Emergency Responder Safety Institute (ERSI)}

ERSI serves as an informal advisory panel of public safety leaders who are committed to reducing deaths and injuries to America's emergency responders. Respondersafety.com has free resources to help protect emergency responders at roadway incidents available in the following topic areas:

\author{
Advance Warning \\ Blocking / Safe Positioning \\ High Visibility PPE \\ Highway Lane Designations \\ Incident Command System (ICS) \& NIMS \\ Line of Duty Deaths (LODD) \\ National Unified Goal \\ Professional Qualifications/Performance Standards \\ Public Education \\ Reports \\ Safety Education Materials \\ Slow Down, Move Over Laws \\ SOP's / SOG's \\ Struck-By Incidents \\ Traffic Incident Management \\ Training \\ Vehicle Emergency Lighting and Markings \\ White Papers.
}

\section{The United States Fire Administration (USFA)}

The USFA and its National Fire Academy are federal agencies working to advance the professional status and expand the knowledge and skills of fire and emergency services personnel. Their free training and education programs support fire departments and emergency services organizations in preparing for, preventing and responding to fires and other hazards. They have developed a number of resources addressing emergency vehicle and roadway operations:

Effects of Warning Lamp Color and Intensity on Driver Vision

Effects of Warning Lamps on Pedestrian Visibility and Driver Behavior

Emergency Vehicle Safety Initiative

Emergency Vehicle Visibility and Conspicuity Study

Inferences about Emergency Vehicle Warning Lighting Systems from Crash Data

International Association of Fire Fighters Apparatus Safety Campaign

Safe Operation of Fire Tankers

Seeing and Stopping Distances

Traffic Incident Management Systems.

\section{National Traffic Incident Management Coalition}

The National Traffic Incident Management Coalition (NTIMC) is a multi-disciplinary partnership forum spanning the public safety and transportation communities to coordinate experiences, 


\section{While Maneuvering Outside His Apparatus, Firefighter Falls into Roadway and Is Struck and Killed by a Delivery Van - Texas}

knowledge, practices, and ideas. NTIMC is committed to safer and more efficient management of all incidents that occur on, or substantially affect, the nation's roadways in order to:

-Enhance the safety of on-scene responders and of motorists passing or approaching a roadway incident

- Strengthen services to incident victims and to stranded motorists

-Reduce incident delay and costs to the traveling public and commercial carriers.

\section{The Federal Highway Administration (FHWA)}

The FHWA is a division of the United States Department of Transportation that specializes in highway transportation. It published the manual on uniform traffic control devices (MUTCD) of which Chapter 6 (Temporary Traffic Control) has particular relevance to the fire service.

\section{National Institute for Occupational Safety and Health (NIOSH)}

NIOSH is the federal agency that conducts research and making recommendations for the prevention of work-related injury and illness. The Fire Fighter Fatality and Prevention Program (FFFIPP) has numerous publications addressing firefighter roadside safety including 34 roadway struck-by fatalities. These reports can be retrieved from the NIOSH FFFIPP website, clicking on: "completed investigations; select a state and fatality type, under trauma's drop-down menu select with motor vehicle-struck by."

\section{Disclaimer}

Mention of any company or product does not constitute endorsement by the National Institute for Occupational Safety and Health (NIOSH), Centers for Disease Control and Prevention. In addition, citations to websites external to NIOSH do not constitute NIOSH endorsement of the sponsoring organizations or their programs or products. Furthermore, NIOSH is not responsible for the content of these websites. All web addresses referenced in this document were accessible as of the publication date. 
MEDIA ADVISORY

FOR IMMEDIATE RELEASE

DATE:
Appendix 1:

CONTACT:

PHONE \& EMAIL:

“Move Over Slow Down” PSA

Helps Public Understand the Importance of Giving First Responders Room to Save Lives on the Roadway

Move Over Slow Down is the Law

WHO: $\quad$ NAME OF DEPARTMENT

In cooperation with ResponderSafety.com

WHAT: $\quad$ PSAs on Move Over Slow Down Laws

Every day across America, distracted and uninformed drivers pose a major threat to the safety and wellbeing of first responders who risk their own lives on roads and highways to assist those involved in traffic incidents. As part of a national effort to reduce the number of first responder fatalities, struck-bys, and near miss incidents, two PSAs from ResponderSafety.com are available to help the public understand their legal and moral responsibility to change lanes and slow down when approaching a stationary emergency response vehicle on the roadway. All 50 states have a Move Over Slow Down law on the books. In NAME OF STATE, our law requires DETAILS OF LAW HERE (see http://www.moveoverlaws.com/).

WHERE: http://www.respondersafety.com/Videos/Slow-Down-Move-Over.aspx http://www.respondersafety.com/Videos/Its-No-Picnic-Out-Here.aspx

WHEN: $\quad$ Available 24/7/365 on the web

WHY: $\quad$ Every year, an estimated average of five firefighters, 12 law enforcement officers, and more than 60 employees of state Departments of Transportation are struck and killed while working roadway incidents. The number of near misses and injuries is far higher, but unknown. ${ }^{1}$ Vehicle-related incidents are the second leading cause of firefighter deaths ${ }^{2}$ and the second leading cause of law enforcement officer deaths ${ }^{3}$.

HOW: $\quad$ The NAME OF DEPARTMENT is available for interviews and further details on the tragedy of first responders being struck by cars while rendering emergency assistance on the roadway in conjunction with these PSAs and the issues they raise.

CONTACT NAME AND INFORMATION OF AVAILABLE INTERVIEWEES

As a public service, media outlets can show the Move Over Slow Down PSAs free of charge. These PSAs inform viewers of the existence of Move Over Slow Down laws and the importance of giving first responders room to work on the roadway — saving lives, helping disabled motorists, and clearing accidents.

\footnotetext{
${ }^{1}$ Source: https://www.fhwa.dot.gov/publications/publicroads/14julaug/05.cfm

${ }^{2}$ Source: http://www.nfpa.org// /media/files/news-and-research/fire-statistics/fire-service/osfff.pdf

${ }^{3}$ Source: http://www.nleomf.org/facts/officer-fatalities-data/causes.html
} 